\title{
Genetic relationships and evolution in Cucurbita pepo (pumpkin, squash, gourd) as revealed by simple sequence repeat polymorphisms
}

\author{
Li Gong • Harry S. Paris • Michael H. Nee • \\ Gertraud Stift · Martin Pachner · Johann Vollmann • \\ Tamas Lelley
}

Received: 26 April 2011 / Accepted: 5 November 2011/Published online: 20 November 2011

(C) The Author(s) 2011. This article is published with open access at Springerlink.com

\begin{abstract}
Genetic relationships among 104 accessions of Cucurbita pepo were assessed from polymorphisms in 134 SSR (microsatellite) and four SCAR loci, yielding a total of 418 alleles, distributed among all 20 linkage groups. Genetic distance values were calculated, a dendrogram constructed, and principal coordinate analyses conducted. The results showed 100 of the accessions as distributed among three clusters representing each of the recognized subspecies,
\end{abstract}

Communicated by I. Paran.

Electronic supplementary material The online version of this article (doi:10.1007/s00122-011-1752-z) contains supplementary material, which is available to authorized users.

L. Gong · G. Stift · M. Pachner · T. Lelley $(\bowtie)$

Department for Agrobiotechnology, Institute for

Biotechnology in Plant Production, University of Natural

Resources and Life Sciences, Vienna, Konrad Lorenz Str. 20,

3430 Tulln, Austria

e-mail: tamas.lelley@boku.ac.at

Present Address:

L. Gong

Department of Plant Pathology, North Dakota State University, Fargo, ND 58108, USA

H. S. Paris

Department of Vegetable Crops and Plant Genetics, Agricultural Research Organization, Newe Ya'ar Research Center, P.O. Box 1021, Ramat Yishay 30-095, Israel

M. H. Nee

Institute of Systematic Botany, New York Botanical Garden, Bronx, NY 10458, USA

J. Vollmann

Department of Crop Sciences, University of Natural

Resources and Life Sciences, Vienna, Konrad Lorenz Str. 20,

3430 Tulln, Austria pepo, texana, and fraterna. The remaining four accessions, all having very small, round, striped fruits, assumed central positions between the two cultivated subspecies, pepo and texana, suggesting that they are relicts of undescribed wild ancestors of the two domesticated subspecies. In both, subsp. texana and subsp. pepo, accessions belonging to the same cultivar-group (fruit shape) associated with one another. Within subsp. pepo, accessions grown for their seeds or that are generalists, used for both seed and fruit consumption, assumed central positions. Specialized accessions, grown exclusively for consumption of their young fruits, or their mature fruit flesh, or seed oil extraction, tended to assume outlying positions, and the different specializations radiated outward from the center in different directions. Accessions of the longest-fruited cultivar-group, Cocozelle, radiated bidirectionally, indicating independent selection events for long fruits in subsp. pepo probably driven by a common desire to consume the young fruits. Among the accessions tested, there was no evidence for crossing between subspecies after domestication.

\section{Introduction}

Cucurbita L. $(2 x=2 n=40)$, a genus native to the Americas with a natural distribution from the USA to Argentina, encompasses pumpkins and squash, which are important food crops throughout temperate, sub-tropical, and tropical regions (Whitaker 1947; Whitaker and Davis 1962). Wild Cucurbita plants are rampant, highly branched vines bearing fruits called "gourds". With some infrequent exceptions, these gourds are small $(<10 \mathrm{~cm}$ diameter $)$, round, smooth, and striped (Bailey 1943; Nee 1990). They have thin, fibrous, bitter flesh enclosing as many as several hundred, small ( $<10 \mathrm{~mm}$ length), flat, nearly elliptical 
seeds. Cultigens of Cucurbita differ from their wild counterparts by often being not as rampantly growing, less branching, and having larger plant parts, especially larger fruits and seeds, and thicker, less fibrous, non-bitter fruit flesh.

Cucurbita pepo L. (Cucurbitaceae) is the species with the greatest monetary value of the genus (Paris 2008). Native to North America, it has been observed growing wild in the southern United States and northeastern Mexico (Bailey 1943; Andres 1987). C. pepo was domesticated twice (Carter 1945; Whitaker and Carter 1946; DeckerWalters 1990; Nee 1990; Lira and Montes 1994; Sanjur et al. 2002). Remains of domesticated C. pepo, 10,000 years old, have been found in Oaxaca, southern Mexico (Whitaker and Cutler 1971; Whitaker and Cutler 1986; Smith 1997). Remains 5,000 years old have been found in eastern North America (Smith 2006). The domesticates typically have larger fruits and seeds than their wild counterparts and a wider range of fruit shapes and colors. C. реро is perhaps the most diverse of all species for fruit characteristics (Duchesne 1786; Naudin 1859; Paris 2007), attributable, in part, to some of its cultigens being grown for eating the immature fruits and others for the mature fruits (Paris 2000a). Fruit size in C. pepo ranges from $30 \mathrm{~g}$ to $20 \mathrm{~kg}$, and fruit shape ranges from spherical to flattened to very long. Fruit surface topography includes smooth, ribbed, lobed, grooved, ridged, furrowed, warted, wrinkled, and combinations of these. Fruit colors are green, orange, and yellow, ranging in intensity and shading from almost black to almost white, and color patterns include striped and bicolored.

The stunning diversity of Cucurbita pepo has been under molecular genetic scrutiny for more than a quarter century, focusing initially on allozyme variation (Ignart and Weeden 1984). Allozyme polymorphisms revealed a fundamental division within C. pepo (Decker 1985, 1988) into three subspecies, C. pepo subsp. pepo, which is known only in cultivation, C. pepo subsp. texana (Scheele) Filov (=C. pepo subsp. ovifera (L.) Decker), known in cultivation and in the wild, and $C$. pepo subsp. fraterna (L. H. Bailey) Lira, Andres \& Nee, known only from wild populations growing in northeastern Mexico (Andres 1987).

The polymorphism of Cucurbita pepo for fruit shape, an easily observable trait under polygenic control (Emerson 1910; Sinnott 1927), led to the proposal that this species be viewed as having eight edible-fruited groups of cultivars (Paris 1986). Accordingly, these are Acorn (turbinate, furrowed), Scallop (flat, lobed), Crookneck (long, narrow necked), Straightneck (long, with proximal constriction), Pumpkin (round or nearly round), Vegetable Marrow (short, tapered cylindrical), Cocozelle (long, bulbous cylindrical) and Zucchini (uniformly cylindrical). The first four cultivar-groups are in $C$. pepo subsp. texana and the last four are in C. pepo subsp. pepo (Paris et al. 2003). Both subspecies also encompass cultivars of ornamental gourds: those of the former subspecies will be referred to here as "Ovifera Gourds" and those of the latter "Pepo Gourds". No genetic barriers preventing crossing between any combination of subspecies, cultivar-groups, or gourds have been reported.

Various DNA-sequence polymorphisms have been employed to examine genetic relationships among Cucurbita pepo accessions with ever-increasing precision, and these have been reviewed by Lebeda et al. (2007). The markers employed have included RAPDs, AFLPs, ISSRs, and SRAPs, as well as a few melon (Cucumis melo L., Cucurbitaceae) SSRs. A study of a wide-based collection of $C$. pepo using AFLPs, ISSRs, and melon SSRs has helped clarify a number of genetic relationships within the species, most notably differentiating the subspecies of Cucurbita pepo and also differentiating their constituents, the cultivar-groups (fruit shapes) within C. pepo subsp. texana, and the Zucchini Group (cultivars with uniformly cylindrical-shaped fruits) from the rest of $C$. реро subsp. pepo (Paris et al. 2003).

Microsatellites or simple sequence repeats, SSRs, are tandemly repeated DNA sequences $1-6$ base pairs long (Queller et al. 1993; Kashi et al. 1997). They are abundant in the genome and unique to species and genera or, to a lesser extent, can be conserved among genera in a plant family (Katzir et al. 1996). Some SSRs have functional significance, in chromatin organization, regulation of gene activity, and recombination ( $\mathrm{Li}$ et al. 2002), but more often they reside in the non-functional part of the genome in seemingly random distribution. Sequences bordering SSRs are highly conserved and provide the opportunity to individualize them by a pair of primers. Once identified, they become signposts, loci, in the genome. Due to the tandem replication of short motifs, SSR loci are prone to replication slippage and unequal crossing over, resulting in length polymorphisms, co-dominant alleles, for these loci. By virtue of their uniqueness, SSR loci are most valuable for studying intra- and interspecific relationships.

Of the first 27 Cucurbita SSRs developed from C. pepo, most were transferable to $C$. moschata Duchesne, $C$. maxima Duchesne, and C. ecuadorensis Cutler \& Whitaker (Stift et al. 2004). Since then, a considerable number of highly transferable SSRs have been developed for the genus Cucurbita. These SSRs have been used for the generation of a more saturated linkage map of $C$. pepo (Gong et al. 2008). The objective of the present work was to further elucidate genetic and evolutionary relationships in $C$. pepo by using a substantial number of SSRs on a large, broadly based collection consisting of more than 100 accessions. 


\section{Materials and methods}

\section{Plant material}

A collection comprising 104 accessions of Cucurbita pepo was chosen for study. The name of each accession, its assigned tripartite abbreviation, country of origin, source of seeds, and plant growth habit are presented in Table 1. Mature fruits of a few of these accessions are depicted in Fig. 1 and others have been depicted elsewhere (Paris 2001). The 104 accessions included 40 of the 45 examined previously using AFLPs, ISSRs, and a few melon, Cucumis melo L., SSRs (Paris et al. 2003). An additional 56 accessions maintained at the Agricultural Research Organization, Newe Ya'ar Research Center, Israel, which have been briefly described and categorized (Paris 2001; Paris and Nerson 2003), were also included. The identity of all accessions was checked and verified by growing out at least eight plants in the field. Except for a few cases, the seedlings used to represent the accessions were not from the original seed samples, as these tended to be comprised of only a few seeds. Instead, the seedlings were grown from seeds obtained by self- or sib-pollinations at Newe Ya'ar. These samples have been collected and maintained since 1978, long before the present investigation was anticipated; in retrospect, the progeny of sib-pollinations could be expected to better represent the original sample populations than the progeny of self-pollinations. A few of the original samples had easily noticeable among-plant variation in vegetative and reproductive characteristics. For such samples, the plants that had been selected for self- or sib-pollination were those that were considered to be most representative of the accession, based on its name, catalogue description, or the majority of the plants observed.

In addition to the 96 accessions that were from the collection maintained at Newe Ya'ar, eight others were sampled, all of which were derived from collections of wild Cucurbita pepo subsp. texana and subsp. fraterna (Table 1). These were obtained from Kathleen Reitsma of the North Central Plant Introduction Station, Ames, Iowa.

The first part of the tri-partite abbreviation assigned to each accession (Table 1) is a single letter, designating subspecies $\mathrm{T}$ for texana, $\mathrm{P}$ for pepo, and $\mathrm{F}$ for fraterna. The second part is a double letter, designating groups of cultivars, such as $\mathrm{AC}$ for acorn, $\mathrm{CN}$ for crookneck, etc. (Paris 1986). The third part is a triple letter or number for the name or number of the accession. Assignment of doubleletter (grouping) abbreviations for the gourds, which received $\mathrm{G}$ as the first of the two letters in the double letter, specifically GF, GO, GP, GQ, GT, and GU, presented some difficulties. First, the term "gourd" refers to small and inedible fruits; however, we have designated as "gourds" the edible-fruited 'Little Gem' (P-GP-LGM) and 'Rolet'
(P-GP-ROL), as these accessions bear small fruits only $7 \mathrm{~cm}$ in diameter (Fig. 1). Second, some of the gourds were not readily assignable to subspecies based on their appearance alone; their respective assignments were made after analyzing the results. 'Miniature Ball' has been found to have an ambivalent position in the species and was not readily assignable to any of the three subspecies (Paris et al. 2003). Also, 'Flat' and 'Flat Striped' could not be readily assigned to any subspecies. These three were given the abbreviations $U$ (Uncertain) for subspecies and GU (Gourd, Uncertain) for cultivar-group (Table 1). Also not readily assignable to subspecies was 'Small Flat Warted', which was given the single-letter designation Q (Questionable) and the double-letter designation GQ (Gourd, Questionable). The designations GO (Gourd, Ovifera) and GT (Gourd, Texana) were used for cultivated and wild gourds, respectively, of subsp. texana.

Three of the gourd accessions used in this study were in fact derived from self-pollinating a single plant in a commercial mixture (Table 1). The accession named 'Oblate Dark Striped' (T-GO-ODS) was derived by self-pollinating a single plant of 'Small Fancy Mixed', seeds of which were obtained from Burpee Seed Co. in 1986; the accession named 'Flat' (U-GU-FLA), which may be identical to the 'Flat' depicted by Shifriss (1965), was derived in the same fashion from the 'Small Warted Blend' mixture of Stokes Seed Co. in 1986; the accession named 'Small Flat Warted' (Q-GQ-SFW) was likewise derived from the 'Ovifera' mixture of Park Seed Co. in 1979. Each of these three derivatives bred true to fruit size, shape, and topography, demonstrating that each was a distinct component (genotype) and not the result of hybridization among plants in the three respective source mixtures.

\section{DNA extraction}

DNA was isolated from fresh young leaves using the Promega Wizard Genomic DNA Purification Kit (Promega, Madison, WI, USA). DNA concentration was determined by the GenQuant RNA/DNA Calculator (Amersham Biosciences Europe, Germany) according to manufacturer's protocol. A minimum of three seedlings per accession were sampled in bulk.

\section{PCR amplification and detection of SSR loci}

Out of the 500 Cucurbita SSR markers developed from genomic DNA by Gong et al. (2008), 138 primer pairs were used of which four turned out to be monomorphic in all accessions. Over $60 \%$ of the SSR markers were derived from $C$. pepo and the remainder from $C$. moschata. Eightytwo of the 134 polymorphic SSR loci have been mapped; they are distributed in all 20 linkage groups fairly evenly, 
Table 1 Classification and sources of seeds of 104 Cucurbita pepo accessions

\begin{tabular}{|c|c|c|c|c|}
\hline Accession name & $\begin{array}{l}\text { Accession } \\
\text { abbreviation }\end{array}$ & Accession pedigree $^{\mathrm{a}}$ & Origin (seed source) & $\begin{array}{l}\text { Plant growth } \\
\text { habit }\end{array}$ \\
\hline Delicata & T-AC-DLC & DLC-1-6-3-1-2-6-5 & Canada (Stokes) & Vine \\
\hline Gill's Golden Pippin & T-AC-GGP & GGP & USA (Seed Savers Exchange) & Vine \\
\hline Jack-Be-Little & T-AC-JBL & JBL-S,Sa & USA (Park) & Vine \\
\hline Royal Acorn & T-AC-RAC & RACc-S & USA (Twilley) & Vine \\
\hline Sweet Dumpling & T-AC-SWD & SWD-3-1-6-2-11 & UK (Thompson \& Morgan) & Vine \\
\hline Table Queen & T-AC-TQE & TQE & USA (Northrup King) & Vine \\
\hline Bianco Friulano & T-CN-BFR & $\mathrm{BFR}-\mathrm{Sa}, \mathrm{Sb}$ & Austria (Arche Noah) & Bush \\
\hline Early Golden Crookneck & T-CN-EAC & $\mathrm{EAC}-\mathrm{Sb}$ & USA (Henry Field) & Bush, open \\
\hline Early Summer Crookneck & T-CN-ESC & ESCc-S & USA (Ledden) & Bush, open \\
\hline Early Yellow Crookneck & T-CN-EYC & EYC-3-3-2-2-1-2-Sb & USA (Twilley) & Bush, open \\
\hline Yellow Summer Crookneck & T-CN-YSC & YSC-3-5-1-S & USA (Ferry Morse) & Bush, open \\
\hline Benning's Green Tint & T-SC-BGT & BGT-6-2-8-2-4-S & USA (Northrup King) & Bush \\
\hline Golden Bush Scallop & T-SC-GBS & GBS-1-4-2 & USA (Dessert) & Bush \\
\hline Patisson Verte Strie de Blanc & T-SC-PVT & PVB-Sa & France (Ducrettet) & Bush \\
\hline White Bush Scallop & T-SC-WBS & WBS-3-Sb & USA (Mandeville) & Bush \\
\hline Yellow Bush Scallop & T-SC-YBS & YBS-S & USA (Gurney) & Bush \\
\hline Creamy & T-SN-CRE & CRE-S & USA (Park) & Bush, open \\
\hline Early Prolific Straightneck & T-SN-EPS & EPS-4-21-2-S & USA (Ferry Morse) & Bush, open \\
\hline Seneca Butterbar & T-SN-SBU & SBUa-Sa & USA (Gurney) & Bush, open \\
\hline Saffron & T-SN-SFF & SFF-S,Sa & USA (Burpee) & Bush, open \\
\hline Straightneck Early Yellow & T-SN-SNE & $\mathrm{SNE}-\mathrm{Sa}, \mathrm{Sb}$ & USA (American) & Bush, open \\
\hline Autumn Wings Medium & T-GO-AWM & AWM-S,SR & USA (Rupp) & Vine \\
\hline Oblate Dark Striped & T-GO-ODS & ODS-6 & USA (Burpee) ${ }^{\mathrm{b}}$ & Vine \\
\hline Shenot's Crown of Thorns & T-GO-SCT & SHC-S & Canada (Stokes) & Vine \\
\hline Striped Pear & T-GO-SPR & SPR & Canada (Stokes) & Vine \\
\hline Wild Texas & T-GT-WTX & WTX-10-Sh & USA (Texas A\&M Univ.) & Vine \\
\hline PI 614684 & T-GT-684 & PI 614684 & Texas, USA (North Central P.I.S.) & Vine \\
\hline PI 614688 & T-GT-688 & PI 614688 & Texas, USA (North Central P.I.S.) & Vine \\
\hline PI 614691 & T-GT-691 & PI 614691 & Texas, USA (North Central P.I.S.) & Vine \\
\hline PI 614693 & T-GT-693 & PI 614693 & Mississippi, USA (North Central P.I.S.) & Vine \\
\hline Wild Mexico 2 & F-GF-WM2 & WMX2-Sa & Tamaulipas, Mexico (Texas A\&M Univ.) & Vine \\
\hline PI 532354 & F-GF-354 & PI 532354 & Tamaulipas, Mexico (North Central P.I.S.) & Vine \\
\hline PI 532355 & F-GF-355 & PI 532355 & Tamaulipas, Mexico (North Central P.I.S.) & Vine \\
\hline PI 532356 & F-GF-356 & PI 532356 & Tamaulipas, Mexico (North Central P.I.S.) & Vine \\
\hline PI 614683 & F-GF-683 & PI 614683 & Tamaulipas, Mexico (North Central P.I.S.) & Vine \\
\hline Flat & U-GU-FLA & FLA-Sa,Sb & Canada $(\text { Stokes })^{\mathrm{c}}$ & Vine \\
\hline Flat Striped & U-GU-FLS & FLS-Sa,Sc & Canada (Stokes) & Vine \\
\hline Miniature Ball & U-GU-MNB & MNB-Sa & Canada (Stokes) & Vine \\
\hline Small Flat Warted & Q-GQ-SFW & SFW-Sa,Sc & USA $(\text { Park })^{\mathrm{d}}$ & Vine \\
\hline Little Gem & P-GP-LGM & LGM-S,Sc & South Africa (MayFord) & Vine \\
\hline Orange Ball & P-GP-ORB & ORB-3-S & Canada (Stokes) & Vine \\
\hline Orange Warted & P-GP-OWA & OWA-4 & Canada (Stokes) & Vine \\
\hline Rolet & P-GP-ROL & $\mathrm{ROL}-\mathrm{Sa}+\mathrm{Sb}, \mathrm{R}$ & South Africa (Unknown) & Vine \\
\hline Alberello di Sarzana & P-CO-ALB & ALB & Italy (S.A.I.S.) & Bush \\
\hline Cocozelle & $\mathrm{P}-\mathrm{CO}-\mathrm{COC}$ & COC-8-12 & USA (Unknown) & Bush, open \\
\hline Cocozelle Tripolis & $\mathrm{P}-\mathrm{CO}-\mathrm{CTR}$ & CTR-S & Germany (Samenzüchter) & Bush, open \\
\hline Lungo Bianco di Sicilia & P-CO-LBS & LBS-S & Italy (S.A.I.S.) & Bush \\
\hline
\end{tabular}


Table 1 continued

\begin{tabular}{|c|c|c|c|c|}
\hline Accession name & $\begin{array}{l}\text { Accession } \\
\text { abbreviation }\end{array}$ & Accession pedigree $^{\mathrm{a}}$ & Origin (seed source) & $\begin{array}{l}\text { Plant growth } \\
\text { habit }\end{array}$ \\
\hline Long Cocozelle & P-CO-LCO & $\mathrm{LCO}-7$ & USA (Ledden) & Bush, open \\
\hline Lungo di Toscana & P-CO-LUT & LUT & Italy (S.A.I.S.) & Bush \\
\hline Romanesco & P-CO-ROM & ROMa-2 & Italy (Semitalia) & Bush \\
\hline San Pasquale & P-CO-SPQ & SPQ & Italy (La Semiorto Sementi) & Bush \\
\hline Striato d'Italia & P-CO-STI & STIa-1 & Italy (S.A.I.S.) & Bush, open \\
\hline Striato Pugliese & P-CO-STP & STPa-S & Italy (Ingegnoli) & Bush \\
\hline Verte d'Italie & P-CO-VIT & VIT & France (Gondian) & Bush, open \\
\hline Verte non-coureuse d'Italie & $\mathrm{P}-\mathrm{CO}-\mathrm{VNI}$ & VNIb-4 & France (Abondance) & Bush, open \\
\hline PI 165018 & P-CO-018 & PI165018-Sa & Turkey (North Central P.I.S.) & Bush \\
\hline IPK 288 & P-CO-288 & IPK288-Sb,Sd & Italy (IPK [Germany]) & Bush, open \\
\hline PI 379307 & P-CO-307 & PI379307-5-3,7 & Kosovo (North Central P.I.S.) & Bush \\
\hline PI 169469 & P-CO-469 & PI169469-S,Sc & Turkey (North Central P.I.S.) & Bush \\
\hline PI 261610 & P-CO-610 & $\mathrm{PI} 261610-\mathrm{Sa}, \mathrm{Sb}$ & Spain (North Central P.I.S.) & Vine \\
\hline PI 357961 & P-CO-961 & PI357961-S & Macedonia (North Central P.I.S.) & Bush \\
\hline Citrouille de Touraine & P-PU-CIR & CIR-Sa & France (Ducrettet) & Vine \\
\hline Connecticut Field & P-PU-CTF & CTFa-S & USA (Ledden) & Vine \\
\hline Dagestan & P-PU-DAG & DAG-S,Sa & Dagestan (N.I.P.B.) & Vine \\
\hline Gourmet Globe & P-PU-GGL & GGL-2-2-2-2-2-2 & USA (Park) & Bush, open \\
\hline Gleisdorfer Ölkürbis & P-PU-GLE & GLE-2,4 & Austria (Saatzucht Gleisdorf) & Vine \\
\hline Jack O’Lantern & P-PU-JOL & JOL-1-21 & USA (Excel) & Vine \\
\hline Mogango sul Mineiro & P-PU-MOG & MOG-Sb,Sc & Brazil (Feltrin) & Vine \\
\hline Nonkadi & P-PU-NOK & NOK-S & Uzbekistan (I.V.S.Q.) & Vine \\
\hline Porqueira & P-PU-PRQ & PRQ & Portugal (Unknown) & Vine \\
\hline Small Sugar & P-PU-SSU & SSUd-1 & USA (Ledden) & Vine \\
\hline Styria & P-PU-STY & STY-2-5-Sa-1/54 & Austria (Unknown) & Vine \\
\hline Tender and True & P-PU-TAT & TAT-S & UK (Sutton’s) & Bush \\
\hline Tondo Chiaro di Toscana & P-PU-TOC & TOCa-S & Italy (C.C.S.A.) & Bush \\
\hline Tondo di Nizza & P-PU-TON & TONa-S & Italy (Ingegnoli) & Bush \\
\hline Tondo Verde Scuro di Piacenza & P-PU-TOS & TOS-3-S & Italy (C.C.S.A.) & Bush \\
\hline Ukrainska Nogoplodna & P-PU-UNO & UNO-2,S & Ukraine (N.I.P.B.) & Vine \\
\hline Wies 371 & P-PU-WIE & STY-2-5-Sa-1 & Austria (Unknown) & Vine \\
\hline Winter Luxury & P-PU-WLU & WLU-26-21 & USA (Jung) & Vine \\
\hline PI 212000 & P-PU-000 & PI212000-S & Iran (North Central P.I.S.) & Vine \\
\hline PI 442309 & P-PU-309 & PI442309-S & Mexico (North Central P.I.S.) & Vine \\
\hline PI 442313 & P-PU-313 & PI442313-S & Mexico (North Central P.I.S.) & Vine \\
\hline IPK 413 & P-PU-413 & IPK413-S,Sa & Italy (IPK [Germany]) & Bush, open \\
\hline PI 169473 & P-PU-473 & PI169473-S & Turkey (North Central P.I.S.) & Vine \\
\hline PI 171628 & P-PU-628 & PI171628-SR,Sa & Turkey (North Central P.I.S.) & Vine \\
\hline PI 458750 Guicoy Grande Verde & P-PU-750 & PI458750-S & Guatemala (North Central P.I.S.) & Vine \\
\hline All Green Bush & P-VM-AGB & AGB-3,7 & UK (Asmer) & Bush \\
\hline Bianco Mezzo Lungho & P-VM-BML & $\mathrm{BML}-\mathrm{Sa}, \mathrm{Sb}$ & France (Seminis) & Bush \\
\hline Blanche non-coureuse & P-VM-BNC & BNCa-S & France (Gondian) & Bush \\
\hline Bolognese & P-VM-BOG & BOG-1-5-9 & Italy (C.C.S.A.) & Bush, open \\
\hline Caserta & P-VM-CAS & CAS-3-9-2 & USA (Northrup King) & Bush, open \\
\hline Dark Green Zucchini & P-VM-DGZ & DGZ-S & USA (Twilley) & Bush \\
\hline Sihi Lavan & P-VM-SLA & SLA-26-17-1-1-29-Sa,b,c-13 & Israel (Aratan) & Bush \\
\hline Table Dainty & P-VM-TDA & TDA-5 & UK (Sutton's) & Vine \\
\hline
\end{tabular}


Table 1 continued

\begin{tabular}{lllll}
\hline Accession name & $\begin{array}{l}\text { Accession } \\
\text { abbreviation }\end{array}$ & Accession pedigree & Origin (seed source) & $\begin{array}{c}\text { Plant growth } \\
\text { habit }\end{array}$ \\
\hline Vegetable Marrow & P-VM-VGM & VGMa-Sa & USA (Ledden) & Bush \\
Verte Petite d'Alger & P-VM-VPA & VPAa-5 & France (Abondance) & Bush, open \\
Vegetable Spaghetti & P-VM-VSP & VSP-4-10-4-Sb & Japan (Sakata) & Bine \\
PI 525179 Alexandria & P-VM-179 & PI525179-S & Egypt (North Central P.I.S.) & Vine \\
M2546 & P-VM-546 & M2546-Sa,b,c & Israel (P.I.S.) & Bush, open \\
Black Zucchini & P-ZU-BZU & BZU-2-Sa & USA (Henry Field) & Bush, open \\
Fordhook Zucchini & P-ZU-FZU & FZUc-2-S & USA (Burpee) & Bush, open \\
Nero di Milano & P-ZU-NER & NER & Italy (C.C.S.A.) & Bush, open \\
True French & P-ZU-TRF & TRF-4-2-1-24-18-2- & UK (Thompson \& Morgan) & Bush, open \\
Zucchini Select & P-ZU-ZSL & ZSL-2-6-S & Canada (Stokes) & \\
\hline
\end{tabular}

Tripartite designation is for subspecies, cultivar-group, and abbreviated accession name, respectively. For subspecies: $T$ texana, $F$ fraterna, $P$ pepo. Other designations used for some of the accessions with regard to their subspecies affiliations are $U$ uncertain and $Q$ questionable. For cultivar-group: $A C$ Acorn, $C N$ Crookneck, $S C$ Scallop, $S N$ Straightneck, $G O$ Ovifera Gourd, $G U$ Uncertain Gourd, GF Fraterna Gourd, $G Q$ Questionable Gourd, GP Pepo Gourd, CO Cocozelle, PU Pumpkin, VM Vegetable Marrow, ZU Zucchini

${ }^{a}$ Accession pedigrees begin with three-letter abbreviations or introduction numbers. Those not followed by hyphens indicate original seed stocks. The number of hyphens following the three-letter abbreviations or introduction numbers indicates the number of generations of self- or sib-pollination. A number following a hyphen indicates self-pollination whilst a capital letter "S" following a hyphen, with or without a lowercase letter, indicates a sib-pollination. For example, the most complex designation, 'Sihi Lavan', indicates 5 generations of self-pollination (-26-17-1-1-29) followed by one generation of three sib-pollinations and bulking the seeds (-Sa,b,c), followed by one more generation of selfpollination (-13)

b True-breeding derivative from 'Small Fancy Mixed'

c True-breeding derivative from 'Small Warted Blend'

d True-breeding derivative from 'Ovifera'

ranging from 2 to 9 per linkage group (Online Resource 1). Four SCAR primer pairs, two developed from co-dominant RAPD and two from co-dominant AFLP markers, were also included in this study. The total volume of the PCR reaction mixture was $10 \mu \mathrm{l}$ and contained 27 ng DNA, 2 mM dNTPs, 0.25 units Taq DNA polymerase, and $1 \times$ reaction buffer containing $1.5 \mathrm{mM} \mathrm{MgCl}_{2}$ (Gene Craft, Germany), 0.25 pmol forward primer with an M13 tail added to its $5^{\prime}$ end (5'-CCCAGTCACGACGTTG-3'), 2.5 pmol reverse primer, and 2.25 pmol fluorescent-labeled M13 tail (FAM, HEX, synthesized by MWG, Ebensburg, D). PCR was performed as follows: denaturation at $95^{\circ} \mathrm{C}$ for $2 \mathrm{~min}$, followed by seven cycles of $45 \mathrm{~s}$ at $94^{\circ} \mathrm{C}, 45 \mathrm{~s}$ at $68^{\circ} \mathrm{C}$ (with each cycle the annealing temp decreases $2^{\circ} \mathrm{C}$ ), and of $60 \mathrm{~s}$ at $72^{\circ} \mathrm{C}$. Products were subsequently amplified for 30 cycles at $94^{\circ} \mathrm{C}$ for $45 \mathrm{~s}, 54^{\circ} \mathrm{C}$ for $45 \mathrm{~s}$, and $72^{\circ} \mathrm{C}$ for $60 \mathrm{~s}$, with a final extension at $72^{\circ} \mathrm{C}$ for $5 \mathrm{~min}$. When primers did not work in this PCR program final annealing temperature was reduced to $48^{\circ} \mathrm{C}$. PCR products were separated using $10 \%$ polyacrylamide gels, $1 \times$ TBE buffer in a C.B.S. electrophoresis chamber (C.B.S. Scientific Inc., Del Mar, CA, USA). Electrophoresis conditions were set at constant $400 \mathrm{~V}$ and $10^{\circ} \mathrm{C}$ for $2 \mathrm{~h}$. Gels were scanned by Typhoon (GE Healthcare, Uppsala, Sweden) in fluorescent mode.
Data analysis

Amplified fragments of each allele were scored as " 1 " (present) or " 0 " (absent). The resulting binary matrix was converted to the required data input format according to the manual of NTSYSpc version $2.11 \mathrm{~S}$ (Exeter Software, Setauket, NY, USA, September 2000) program.

Genetic similarity among accessions, based on the presence or absence of alleles, was calculated using the Dice (Nei and Li 1979) coefficient of similarity/dissimilarity. Genetic distance (GD) values were calculated as 1- (one minus) the coefficient of similarity. From the similarity matrix, a dendrogram was constructed using the UPGMA clustering method. The robustness of the phylogenetic tree was evaluated by bootstrap analysis with 5,000 replicates using the bootstrap function of the FreeTree program (Hampl et al. 2001).

Principal coordinate analyses (PCOORDA) were carried out using the Dice genetic distance matrix and the DCENTER and EIGEN program options of NTSYSpc. Distributions of the accessions were depicted in twodimensional scatter plots using the first and second principal coordinates. 


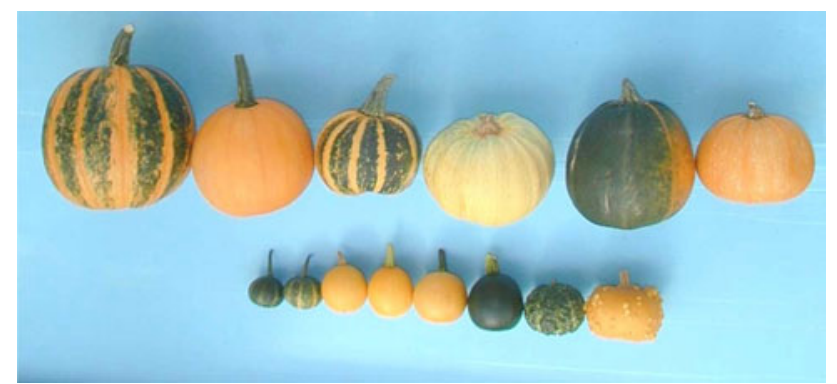

Fig. 1 Mature fruits of six Cucurbita pepo pumpkins (top row) and eight Cucurbita pepo gourds (bottom row). Left to right, with their dimensions $(\mathrm{cm}$, polar diameter $\times$ equatorial diameter, not including the "warts"). Pumpkins: 'Gleisdorfer Ölkurbis', P-PU-GLE $(18 \times 19)$, 'Winter Luxury', P-PU-WLU $(14 \times 15)$, 'Gourmet Globe', P-PU-GGL $(11 \times 13)$, 'Tondo Chiaro di Toscana', P-PUTOC $(11 \times 16)$, 'Tondo Verde Scuro di Piacenza', P-PU-TOS $(15 \times 16)$, and 'Tondo di Nizza', P-PU-TON $(9 \times 13)$. Gourds: 'Miniature Ball', U-GU-MNB $(4 \times 5)$, 'Flat', U-GU-FLA $(4 \times 6)$, 'Orange Ball, P-GP-ORB $(6 \times 6)$ ', 'Orange' $(7 \times 6)$ (not included in this investigation), 'Little Gem', P-GP-LGM $(7 \times 7)$, 'Rolet', P-GPROL $(7 \times 7)$, 'Small Flat Warted', Q-GQ-SFW $(6 \times 8)$, and 'Orange Warted', P-GP-OWA $(6 \times 10)$

\section{Results}

The 134 SSR and 4 SCAR loci yielded a total of 418 alleles. The average number of alleles per locus was 3.0, with $37 \%$ of the loci having two alleles, $37.7 \%$ having three, $15.2 \%$ four, $8.7 \%$ five, one locus $(0.7 \%)$ having six and one $(0.7 \%)$ having 11 alleles. Average heterozygosity within accessions was low, 7.6\% (Online Resource 2). Unusually high heterozygosity, $>20 \%$, was observed within three edible-fruited cultivars of subsp. pepo, P-VMBNC, P-PU-CTF, and P-CO-CTR, and an ornamentalgourd fruit-color mixture of subsp. texana, T-GO-AWM. The wild accessions, F-GF and T-GT, had average heterozygosities that were quite low, $<5 \%$.

Genetic distance values

The average genetic distance (GD) values among the subspecies were high (Table 2; GD values between individual accessions are presented in Online Resource 3). The Cucurbita pepo subsp. fraterna gourds (F-GF) had an average GD value of 0.54 with the subsp. texana $(\mathrm{T})$ groupings and 0.60 with the subsp. pepo $(\mathrm{P})$ groupings. The average GD value between the subsp. texana groupings and the subsp. pepo groupings was even higher, 0.67. The lowest average GD value for subsp. fraterna gourds was 0.51 , with the wild gourds of subsp. texana (T-GT).

The gourds of uncertain and questionable classifications, U-GU and Q-GQ, had high average GDs with the subsp. fraterna gourds (F-GF), 0.62 and 0.59, respectively, but had markedly lower average GDs with the two domesticated subspecies (Table 2). The U-GU gourds had average GDs of 0.49 and 0.54 with subsp. texana (T) and subsp. pepo $(\mathrm{P})$, respectively, and the corresponding average GDs of the Q-GQ gourd were 0.54 and 0.46 .

Average GDs among groupings within the same subspecies were lower (Table 2). These ranged from 0.30 to 0.41 , averaging 0.38 , within subsp. texana and were even lower, $0.27-0.38$, averaging 0.33 , within subspecies pepo.

Table 2 Genetic distances within (diagonal) and between Cucurbita pepo groupings based on SSR and SCAR markers

\begin{tabular}{|c|c|c|c|c|c|c|c|c|c|c|c|c|c|c|}
\hline & $\mathrm{T}-\mathrm{AC}$ & $\mathrm{T}-\mathrm{CN}$ & T-GO & T-GT & T-SC & T-SN & F-GF & $\mathrm{P}-\mathrm{CO}$ & P-GP & P-PU & P-VM & P-ZU & Q-GQ & U-GU \\
\hline $\mathrm{T}-\mathrm{AC}$ & 0.26 & & & & & & & & & & & & & \\
\hline $\mathrm{T}-\mathrm{CN}$ & 0.39 & 0.24 & & & & & & & & & & & & \\
\hline T-GO & 0.40 & 0.41 & 0.38 & & & & & & & & & & & \\
\hline T-GT & 0.39 & 0.41 & 0.38 & 0.17 & & & & & & & & & & \\
\hline T-SC & 0.37 & 0.33 & 0.37 & 0.35 & 0.28 & & & & & & & & & \\
\hline T-SN & 0.40 & 0.29 & 0.41 & 0.41 & 0.34 & 0.12 & & & & & & & & \\
\hline F-GF & 0.56 & 0.53 & 0.55 & 0.51 & 0.56 & 0.52 & 0.17 & & & & & & & \\
\hline $\mathrm{P}-\mathrm{CO}$ & 0.67 & 0.66 & 0.66 & 0.73 & 0.71 & 0.63 & 0.59 & 0.27 & & & & & & \\
\hline P-GP & 0.65 & 0.62 & 0.63 & 0.68 & 0.68 & 0.60 & 0.58 & 0.36 & 0.34 & & & & & \\
\hline P-PU & 0.67 & 0.65 & 0.66 & 0.73 & 0.71 & 0.63 & 0.59 & 0.30 & 0.36 & 0.29 & & & & \\
\hline $\mathrm{P}-\mathrm{VM}$ & 0.66 & 0.65 & 0.66 & 0.72 & 0.71 & 0.63 & 0.60 & 0.30 & 0.37 & 0.31 & 0.32 & & & \\
\hline P-ZU & 0.67 & 0.67 & 0.66 & 0.73 & 0.72 & 0.60 & 0.62 & 0.27 & 0.36 & 0.32 & 0.30 & 0.10 & & \\
\hline Q-GQ & 0.57 & 0.52 & 0.53 & 0.56 & 0.52 & 0.52 & 0.59 & 0.46 & 0.47 & 0.44 & 0.45 & 0.46 & $-{ }^{\mathrm{a}}$ & \\
\hline U-GU & 0.51 & 0.49 & 0.43 & 0.50 & 0.50 & 0.48 & 0.62 & 0.55 & 0.51 & 0.53 & 0.54 & 0.56 & 0.47 & 0.23 \\
\hline
\end{tabular}

Single letters: $T$ subsp. texana, $F$ subsp. fraterna, $P$ subsp. pepo, $Q$ questionable, $U$ uncertain. Double letters: $A C$ Acorn, $C N$ Crookneck, $G O$ Ovifera Gourd, GT Texana Gourd, SC Scallop, SN Straightneck, GF Fraterna Gourd, CO Cocozelle, GP Pepo Gourd, PU Pumpkin, VM Vegetable Marrow, $Z U$ Zucchini, $G Q$ Questionable Gourd, $G U$ Uncertain Gourd

${ }^{\text {a }}$ Only one accession in grouping 
Average GDs among accessions within groupings were lower than average GDs among groupings in almost all cases (Table 2). In subsp. texana, the only exception was among the Ovifera Gourd cultivars (T-GO), which had a slightly higher average GD among themselves (0.38) than the average of them from the Scallop group (T-SC) (0.37). In subsp. pepo, the vegetable marrow cultivars (P-VM) had a slightly higher within-group average GD (0.32) than with the other three edible-fruited cultivar-groups. In both subsp. texana and subsp. pepo, the ornamental gourds (T-GO, P-GP) had the highest within-group average GDs, 0.38 and 0.34 , respectively. Moreover, average GD values among the edible-fruited subsp. pepo cultivar-groups (P-CO, P-PU, P-VM, P-ZU) were considerably lower than of each with the pepo ornamental gourds (P-GP), 0.38. Within-grouping average GDs were lowest for the Straightneck Group (T-SN, 0.12), the Zucchini Group (P-ZU, 0.10), the wild gourds of subsp. texana (T-GT, 0.17 ), and the wild gourds of subsp. fraterna (F-GF, 0.17).

\section{Dendrogram}

The dendrogram consists of two distinct clusters (Fig. 2). The smaller one, encompassing 38 accessions, is divided into a number of clearly defined sub-clusters. The most outlying sub-cluster is comprised of the five accessions of Cucurbita pepo subsp. fraterna, F-GF. The next most outlying sub-cluster is formed by the three smooth, very small, striped ornamental gourds, U-GU. The rest of the cluster contains all 30 accessions of subsp. texana. The wild gourds, T-GT, form a tight sub-cluster. The six accessions of the Acorn Group, T-AC, form another subcluster, within which these six accessions pair with one another according to mature fruit exterior color, dark green, T-AC-RAC and T-AC-TQE, orange, T-AC-GGP and T-AC-JBL, and cream-and-green striped, T-AC-DLC and T-AC-SWD. Two other sub-clusters represent the Straightneck Group, T-SN, and Crookneck Group, T-CN. The five cultivars of the Scallop Group, T-SC, form a looser sub-cluster. The remaining four accessions, all Ovifera Gourds, T-GO, are more dispersed and one, T-GOSCT, assumes an outlying position.

The larger cluster of the dendrogram is comprised of 66 accessions but contains few sub-clusters having bootstrap values of $\geq 50$ (Fig. 2). All of the gourds in this cluster are outliers. The most outlying is the questionable gourd, Q-GQ-SFW. A smooth, spherical Pepo Gourd, P-GP-ORB, is the next most outlying accession in this cluster. Also outlying are the edible South African "gourds", P-GP-ROL and P-GP-LGM, which associate closely with one another but not with P-GP-ORB, which the latter superficially resembles (Fig. 1). The most distinct, tightest sub-cluster is formed by the five cultivars of the Zucchini Group, P-ZU.
The three accessions of oil-seed pumpkins, PU-GLE, PUSTY, and PU-WIE, also form a sub-cluster. Pairings are found between two strongly and interstitially ribbed pumpkins, PU-750 and PU-MOG, two Turkish pumpkins, PU-473 and PU-628, two French, relatively short cocozelles, CO-VIT and CO-VNI, and between a pumpkin, PUNOK, and a short vegetable marrow, VM-VSP. The 25 accessions of the Pumpkin Group, P-PU, are spread across this cluster and are not robustly separated from those of the Vegetable Marrow Group, P-VM, and the Cocozelle Group, P-CO.

\section{Principal coordinate analyses}

The scatter plot based on principal coordinate analysis for Cucurbita pepo shows the five C. pepo subsp. fraterna gourds, F-GF, in a position far from all of the other accessions (Fig. 3). On the other hand, the three smooth, very small, striped gourds, U-GU, occupy a central position between the accessions of $C$. pepo subsp. texana and C. реро subsp. реро, but slightly skewed toward the former. Noteworthy is the position of the Q-GQ gourd, between the U-GU gourds and the 65 accessions of $C$. pepo subsp. pepo.

The scatter plot for the subsp. texana cluster (Fig. 4) reveals close associations among accessions of the same cultivar-group, including the association of the crown gourd, GO-SCT, with the other GO gourds. These gourds appear rather distant to the wild gourds, GT, but quite close to the accessions of the Scallop Group, SC. The accessions of the Acorn Group, AC, have a loose association with the phenotypically most deviant of them in shape, AC-DLC. $\mathrm{CN}-\mathrm{YSC}$ is seen as a link between the other accessions of the Crookneck Group, $\mathrm{CN}$, and the cluster formed by the accessions of the Straightneck Group, SN.

The scatter plot based on the principal coordinate analysis of subsp. pepo (Fig. 5) has the five accessions of the Zucchini Group (ZU) together at the extreme left. Nearest to them are two other open bush accessions, VMCAS and PU-GGL (Table 1). Collectively these seven accessions appear as a continuation of a swath of open bush Italian accessions of the Cocozelle Group (CO). The oilseed pumpkins, PU-GLE, PU-STY, and PU-WIE, are distributed fairly close to one another, but at the opposite end of the scatter plot, to the right. The two edible gourds from South Africa, GP-LGM and GP-ROL, are also outliers, but in a third direction, toward the bottom.

Another salient feature of the scatter plot for subsp. pepo (Fig. 5) is a region in which the accessions are densely distributed. This central "core" encompasses 18 of the 25 accessions of the Pumpkin Group (PU). Sixteen of these 18 pumpkins have plants that are late-maturing and viney (Table 1). The two most strongly and interstitially ribbed 
Fig. 2 Rooted dendrogram derived from UPGMA cluster analysis of 104 Cucurbita pepo accessions. The tripartite designations are as in Table 1, with single letters representing subspecies, double letters representing groupings, and triple letters representing accessions. Numbers at the nodes are bootstrap percentages out of 5,000. Only values of $\geq 50$ are indicated

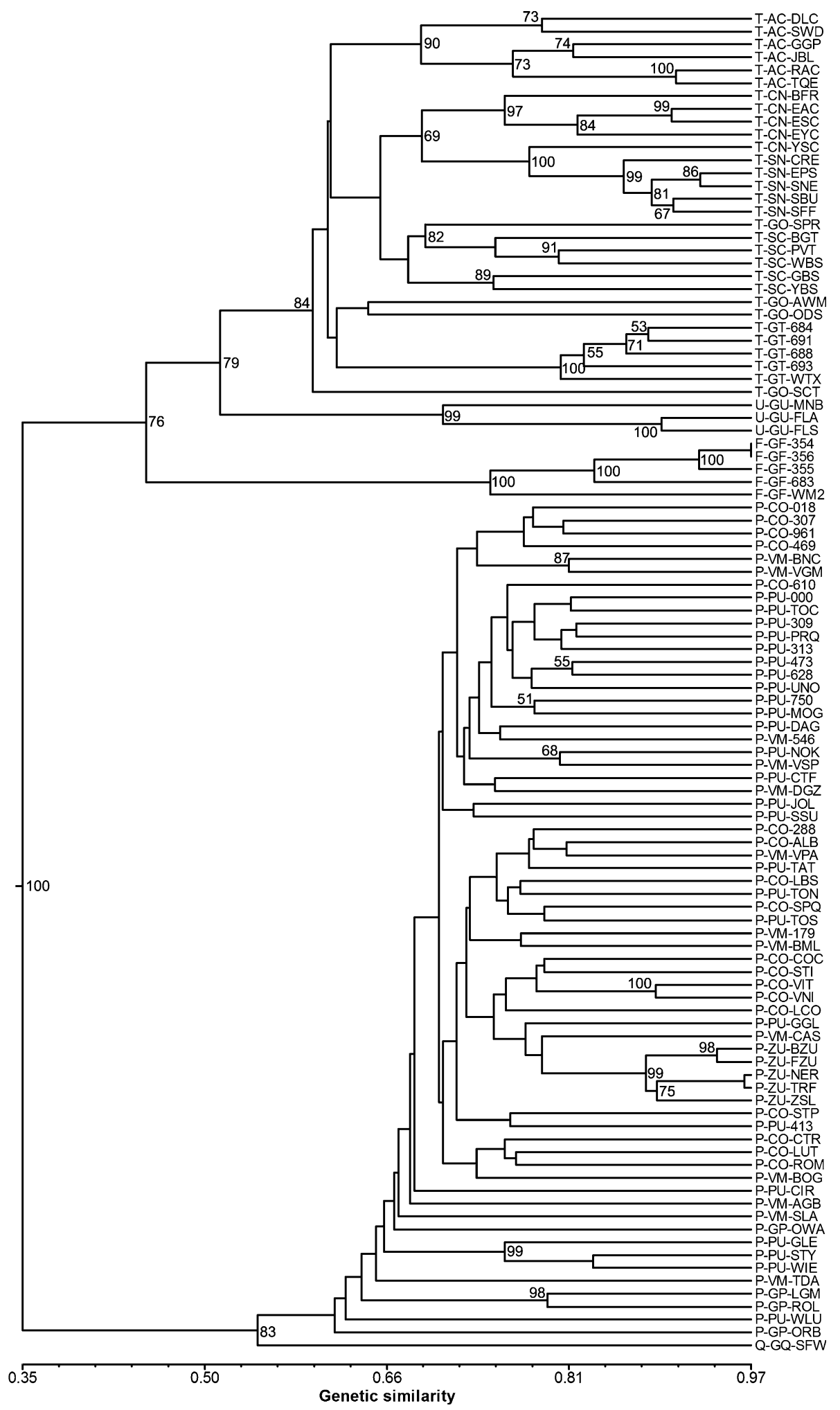

pumpkins, PU-MOG and PU-750, are positioned almost dead center in this core. The four orange, grooved pumpkins from the USA, PU-JOL, PU-WLU, PU-CTF, and PU$\mathrm{SSU}$, are bunched in its lower portion. Several vegetable marrows (VM) are found among the pumpkins of the central core; these include two viney accessions, VM-TDA and VM-546, and one having a closed bush habit, VMDGZ. Several cocozelles (CO) are also found within the core; these are a viney accession from Spain, CO-610, and the two Italian accessions having bushy but late-bearing 


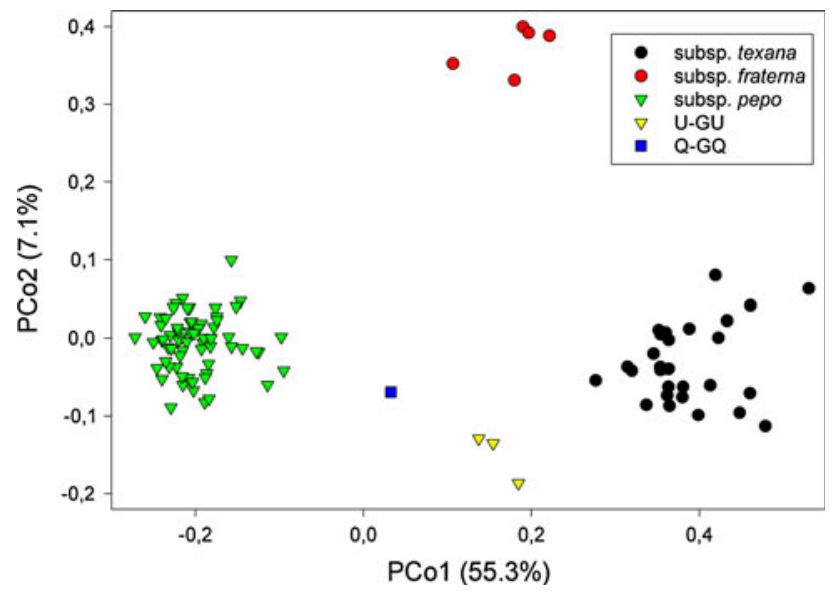

Fig. 3 Scatter plot based on principal coordinate analysis (PCoord $1 \times$ PCoord2) for 104 accessions of Cucurbita pepo. $Q-G Q$ questionable gourd, $U-G U$ uncertain gourd

plants and strongly ribbed fruits, CO-ROM and CO-LUT. These three cocozelles, three vegetable marrows, and two pumpkins having bushy plants, PU-TAT and PU-TOC, are all bunched toward the left of the central core.

Just outside the central core, to the left, are three Italian pumpkin accessions having bushy plants, PU-TON, PUTOS, and PU-413 (Table 1; Fig. 5). Most of the vegetable marrows are on the outskirts of the core but they appear in a bidirectional distribution; towards the top are four bush accessions, VM-AGB, VM-BNC, VM-VGM, and VMVPA and towards the left, quite close to the Italian bush pumpkins, are three other bush vegetable marrows, VMBML, VM-BOG, and VM-SLA, the former two being
Italian cultivars. Nearly all of the cocozelles are outside the core and also in a bidirectional distribution. The bush accessions from the Balkans and Turkey, CO-018, CO-307, CO-469, and CO-961, are located towards the top, nearest to but beyond four bush vegetable marrows. The rest of the cocozelles, most being open bush, early maturing, and of Italian ancestry, are located towards the left, in a swath extending far beyond the core toward the zucchinis (ZU).

\section{Discussion}

Using SSR markers for determining genetic relationships in Cucurbita pepo

SSR markers were used previously to determine genetic relationships among highly diverse accessions of Cucurbita pepo, but to a limited extent. Only seven SSRs derived from Cucumis melo (melon) were used on 45 accessions (Paris et al. 2004). The first 22 SSR markers developed from Cucurbita were used in a study focusing on oil pumpkins, C. pepo subsp. pepo Pumpkin Group (Stift et al. 2004). More recently, over 500 SSR markers of $C$. pepo and C. moschata became publicly available, allowing construction of the first SSR-based genetic linkage map of Cucurbita (Gong et al. 2008). In the present study, 134 SSR and 4 SCAR markers were included, 82 of which are mapped; the distribution of the mapped markers encompasses all 20 linkage groups (Online Resource 1) and positions of these markers on the map have been presented by Gong et al. (2008). As SSRs are considered to be highly polymorphic and mutable (Kashi and
Fig. 4 Scatter plot based on principal coordinate analysis (PCoord $1 \times$ PCoord2) for the 30 accessions of Cucurbita pepo subsp. texana. AC Acorn, $C N$ Crookneck, GO Ovifera Gourd, GT Texana Gourd, SC Scallop, $S N$ Straightneck. The 30 accession abbreviations are as in Table 1

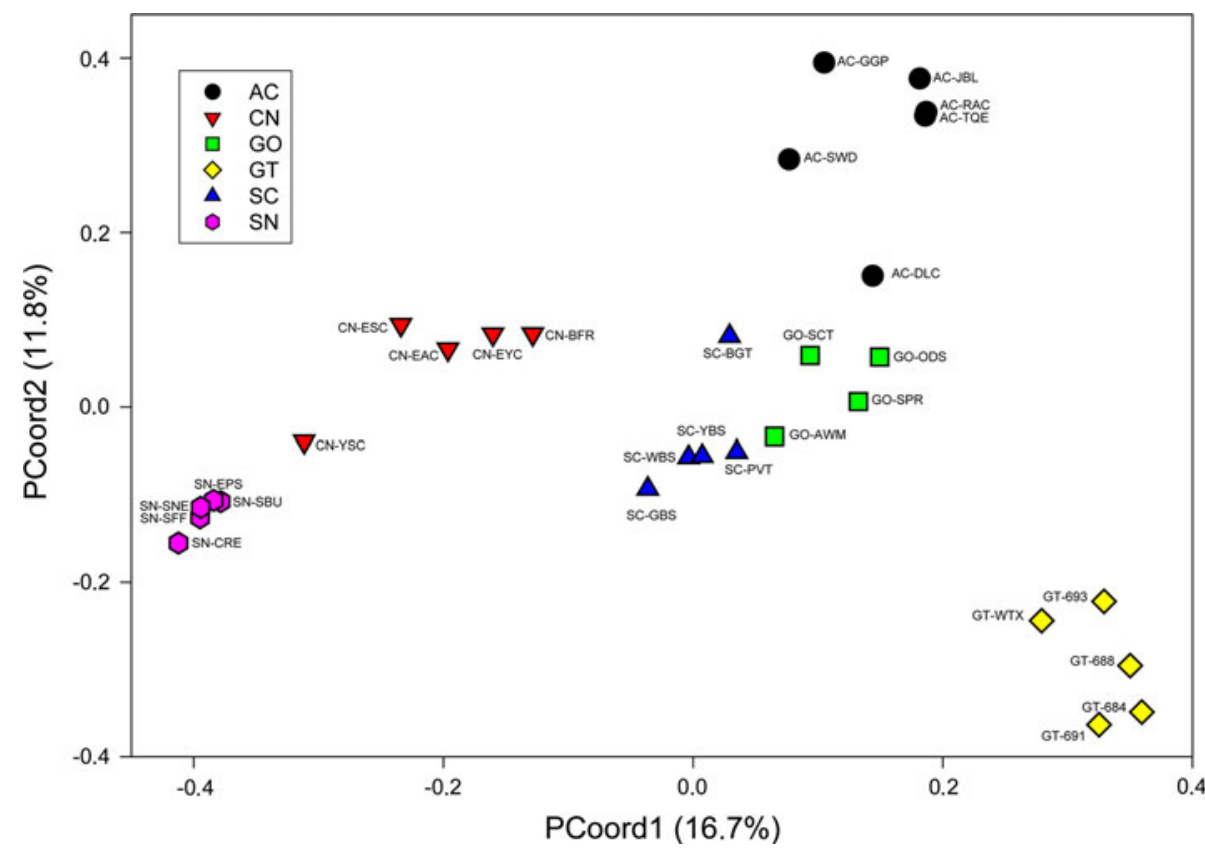


Fig. 5 Scatter plot based on principal coordinate analysis (PCoord $1 \times$ PCoord2) for 65 accessions of Cucurbita pepo subsp. pepo. $C O$ Cocozelle, GP Pepo Gourd, $P U$ Pumpkin, $V M$ Vegetable marrow, $Z U$ Zucchini. The 65 accession abbreviations are as in Table 1. The circle indicates the central core of subsp. pepo accessions

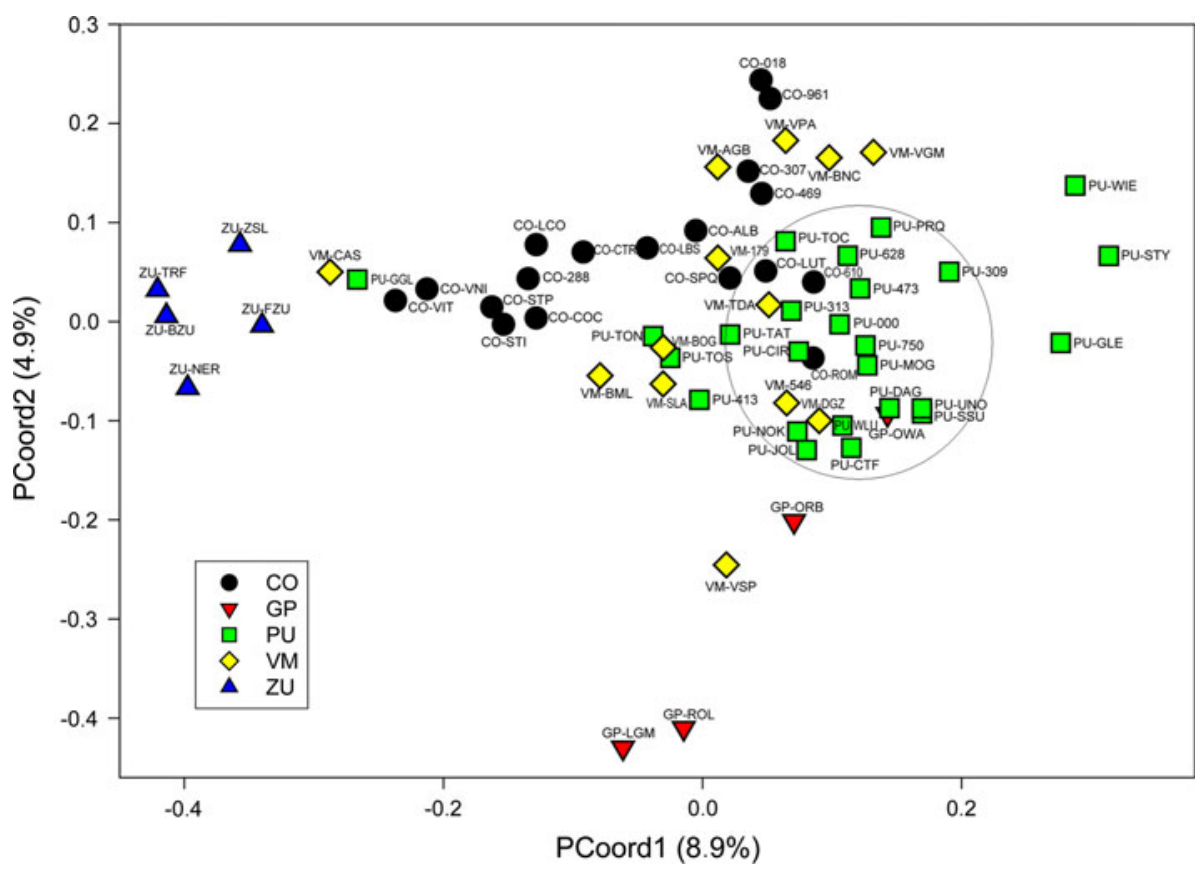

King 2006; King et al. 2006), it is surprising that for 134 loci from such a large, broadly based collection (Table 1) of a phenotypically highly polymorphic species, the average number of alleles per locus was only 3.0. Recently, Blanca et al. (2011) reported the generation of $>500,000$ C. pepoEST sequences from which they obtained nearly 50,000 Cucurbita unigenes. Using a cultivar of the Zucchini Group and one of the Scallop Group, they identified a set of 1,882 unigenes having SSR motifs. Also, using a set of 30 ESTSSRs tested on 10 Cucurbita genotypes, nine from C. pepo and one from C. moschata, they found 3.2 alleles per primer pair. A possible explanation for the unexpectedly low number of alleles observed by Blanca et al. (2011) and by us would be that these sequences have a functional role. Considering the small size of the pumpkin genome, ca. $0.55 \mathrm{pg}$, and that more than $70 \%$ of the SSRs used in the present study had only two or three alleles, it appears likely that a substantial portion of these SSRs is located within gene sequences.

The large number of accessions used in the present investigation, 104 (Table 1), is approximately double that used in each of the previously most comprehensive studies of Cucurbita pepo, by Paris et al. (2003) and Ferriol et al. (2003). The use of SSR markers in so large a quantity and scored for over 400 alleles, with distribution in all 20 linkage groups, provides a fairly broad coverage of the genome. Earlier studies did not include presentation of scatter plots derived from principal coordinate analyses for each subspecies separately; these, in the present investigation (Figs. 4, 5), provide different perspectives from that of the species as a whole (Fig. 3) and from the dendrogram (Fig. 2). Consequently, the present results offer a new and clearer visualization of genetic relationships and evolution within this species that inspire a markedly improved degree of confidence.

The three subspecies of Cucurbita pepo

The results (Fig. 2) show two main clusters within Cucurbita pepo, one corresponding to C. pepo subsp. pepo and the other including $C$. pepo subsp. texana and $C$. pepo subsp. fraterna. These results, together with the GD values (Table 2), are consistent with those of previous investigations employing organellar (Wilson et al. 1992; Sanjur et al. 2002) and nuclear (Paris et al. 2003) DNA markers showing that subsp. fraterna is closer to subsp. texana than it is to subsp. pepo. However, subsp. pepo is somewhat closer to subsp. fraterna than to subsp. texana (Table 2) and thus the two cultivated subspecies are the most divergent.

The gourds of the three subspecies

The five wild gourd accessions of Cucurbita pepo subsp. fraterna, F-GF, were collected in the state of Tamaulipas, northeastern Mexico (H.D. Wilson, pers. comm.; K. Reitsma, pers. comm.). They are genetically very distant to all accessions of the other two subspecies but closer to subsp. texana than to subsp. pepo (Table 2; Figs. 2, 3). It has been proposed that subsp. fraterna is ancestral to subsp. pepo 
(Andres 1987), but the great distance of the subsp. fraterna accessions from those of subsp. pepo does not favor this idea.

The five wild gourd accessions of Cucurbita pepo subsp. texana, T-GT, were collected in the southeastern USA (Table 1; K. Reitsma pers. comm.). The average GD value among these five wild accessions is low, 0.17, markedly lower than for most of the cultivar-groups (Table 2). Genetic variation observed among wild populations of subsp. texana led to the assertion that populations from within and from outside Texas should be treated as separate botanical varieties (Decker-Walters et al. 2002). However, the low average GD values observed here and in an earlier investigation (Paris et al. 2003) do not support a varietal treatment based on geography.

The four representatives of Ovifera Gourds, T-GO, had by far the highest average within-group GD value of subsp. texana (Table 2), consistent with the differing fruit shapes of these accessions. They are found near one another in the principal coordinate analysis and close to the accessions of the Scallop Group (T-SC) (Fig. 4). It has been asserted that Ovifera Gourds and squash may have crossed with one another during their evolution under domestication to produce new cultigens of ornamental gourds (Shifriss 1965). From Fig. 4, this assertion can be made more specific, viz., crossing between these gourds and scallop squash. Moreover, such crossing could have also resulted in the development of new edible cultivars, as suggested by the results of Duchesne's experiments on crossability in Cucurbita (Paris 2000b).

The four representatives of Pepo Gourds, P-GP (subsp. реро), like their counterparts in subsp. texana, had the highest within-group GD value of the subspecies (Table 2). All four, though, had nearly the same round fruit shape (Fig. 1).

The uncertain and questionable gourds

In previous investigations, 'Miniature Ball' (U-GU-MNB), appeared closer to subsp. pepo (Decker and Wilson 1987) or in an ambivalent position (Paris et al. 2003). Presently, the three Uncertain Gourds, U-GU, and one Questionable Gourd, Q-GQ, are positioned clearly outside of the three subspecies clusters (Fig. 3). The average GD values for the U-GU gourds from the accessions of subsp. texana and subsp. pepo are, respectively, 0.48 and 0.54 ; the average GD values of Q-GQ-SFW from the accessions of these two subspecies are, respectively, 0.54 and 0.46 (Table 2). Although these GDs average less than those separating the three recognized subspecies (fraterna-texana 0.54 , texanapepo 0.67 , pepo-fraterna 0.60 ), they are nonetheless considerably higher than those among groups within the two domesticated subspecies, which range from 0.27 to 0.37 in subsp. pepo and 0.29 to 0.41 in subsp. texana (Table 2).
The average GD between the Q-GQ gourd and the three U-GU gourds was also high, 0.47 (Table 2). These results could justify considering the Q-GQ and U-GU gourds as representing two additional, separate subspecies. Notably, the locations of the Q-GQ and U-GU gourds, between the clusters of subsp. pepo and subsp. texana (Fig. 3), are where ancestors of subsp. pepo and subsp. texana would be expected.

Wild Cucurbita plants have small fruits (Bailey 1943; Nee 1990). The U-GU gourds have the smallest fruit size known in Cucurbita pepo, even smaller than gourds collected from wild accessions (Paris et al. 2003). The very small-fruited U-GU-FLA (Fig. 1) was isolated from a commercial mixture of gourd seeds (Table 1). Indeed, unlike cultivars that are grown for culinary use, seeds of many cultivated gourds are sold not as genetically uniform stocks but as mixtures. Growers of ornamental gourds desire phenotypes sharply differing in shape, color, color pattern, and fruit surface topography. To ensure maintenance of these differences, each component of commercial gourd mixtures must be reproduced in isolation. We observed directly, by self-pollination and progeny testing in the field, that these components are morphologically true-breeding. Although the central placement of the Q-GQ and U-GU gourds (Fig. 3) could be the result of crossing between subsp. pepo and subsp. texana, this possibility appears remote as the U-GU gourds are even smaller than the wild F-GF and T-GT gourds and there is no apparent reason for selection of plants bearing fruits even smaller than those borne by wild plants. The heterozygosity of the U-GU gourds was low, averaging 8.0\% (Online Resource 2). Moreover, the Q-GQ and U-GU gourds retain the wildtype nearly round shape and broad dark green-striped color pattern (Fig. 1), thus lacking a novelty indicative of artificial selection. The central positions of the Questionable Gourd and Uncertain Gourds, between subsp. pepo and subsp. texana, implicate them as relicts of undescribed wild progenitors.

The ultimate place of origin of the smallest gourds is unknown. A pyriform, striped gourd of Cucurbita pepo subsp. texana, the earliest known Cucurbita to have been depicted in Europe, was probably grown from seeds collected from a wild plant (Paris et al. 2006). Subsequently, gourds were prolifically illustrated and described in Renaissance herbals and later works, notably in the Vienna Codex of Leonhart Fuchs (mid-16th century), the Historia Plantarum Universalis of Jean Bauhin (early 17th century), Duchesne's collection of drawings for his Essai sur l'histoire naturelle des courges (late 18th century), and Vilmorin's Les Plantes Potagères (late 19th century) (Paris 2000a, b; Paris 2007). The depictions show a number of gourds that appear quite similar to some of the accessions used in the present work, including GP-ORB, GO-SPR, 
GU-FLS, and GU-MNB. Unfortunately, for all of these gourds, the locality of collection is unknown.

Lack of crossing between subspecies

The GD values observed among the subsp. pepo groupings range from 0.27 to 0.37 and among the subsp. texana groupings from 0.33 to 0.41 (Table 2). The GD values between groupings of subsp. pepo and groupings of subsp. texana are considerably higher, ranging from 0.60 to 0.73 . The GD values between the groupings of both subspecies with subsp. fraterna are also higher, ranging from 0.51 to 0.62 , than comparisons among groupings within subspecies. There was no unusually low GD value between one of the 65 accessions of subsp. pepo with one of the 30 of subsp. texana or five of subsp. fraterna (Online Resource 3). Hence, in this collection, there is no evidence for crossing between subspecies in the evolution under domestication of $C$. реро. The proposal that the Acorn Group (T-AC) may have been derived from a cross between a Pumpkin (P-PU) and an ornamental, ovifera gourd (T-GO) (Paris 1989) is untenable.

Some mutant traits are common in both domesticated subspecies. The same incompletely dominant allele for bush growth habit, $B u$ (Edelstein et al. 1989), is common in subsp. pepo and subsp. texana. The same recessive mutants, $h r$ for non-lignified rinds and $b i$ for non-bitter fruits, occur in both subspecies, as inter-subspecific crosses between non-lignified, non-bitter genotypes have yielded only non-lignified, non-bitter progeny (Schaffer et al. 1986; Paris and Brown 2005). These and other traits associated with evolution under domestication, including increased fruit size, deviation from fruit roundness, and open growth habit, were likely selected independently in the two cultivated subspecies, given the high GD values observed for all inter-subspecific combinations (Table 2; Online Resource 3).

The edible-fruited cultivar-groups of subsp. texana

Cucurbita pepo subsp. texana is divided into distinct subclusters (Figs. 2, 4), four of which are based on the ediblefruited cultivar-groups that were defined by fruit shape and named Acorn, Crookneck, Scallop, and Straightneck (Paris 1986). Average GD values among cultivars within these cultivar-groups were markedly lower than those among the cultivar-groups (Table 2), corroborating results of previous inquiries (Katzir et al. 2000; Paris et al. 2003, 2004; Ferriol et al. 2003). Furthermore, in the sub-cluster of the Acorn Group, the cultivars paired with one another according to exterior fruit color, as already observed by Ferriol et al. (2003) using SRAP markers.
Average within-group GDs of this subspecies (Table 2) were often markedly greater than those obtained in a previous study by Paris et al. (2004). Presently, far more SSR alleles were scored and more accessions were included, some of which had lesser affinity, based on fruit shape, to a particular cultivar-group (Paris 1986). For example, the Acorn Group (T-AC) had a GD of 0.26 now and only 0.05 previously but 'Delicata' (T-AC-DLC), included presently but not previously, does not have the typical turbinate shape of fruits of the Acorn Group. Consistent with its atypical shape, it had high GDs to the other acorn cultivars, averaging 0.32 (Online Resource 3) and this relatively distant position is readily apparent in the principal coordinate analysis (Fig. 4).

Principal coordinate analysis places the Scallop Group (T-SC) in the most central position within Cucurbita pepo subsp. texana and, of the edible-fruited cultivar-groups, closest to the wild (T-GT) gourds (Fig. 4). Thus, it appears likely that it was the first edible-fruited cultivar-group to have evolved and diversified under the guidance of the preColumbian, Native Americans of what is now the United States. Findings of rind fragments of different fruit forms, including lobed, furrowed, and warted, at sites 2,5003,000 years old in Kentucky, are suggestive of incipient differentiation into the Scallop (T-SC), Acorn (T-AC), and Crookneck (T-CN) Groups (Watson and Yarnell 1966, 1969; Cowan 1997). These three cultivar-groups can be thought of as products of pre-Columbian genetic drift and conservation in isolation that occurred in eastern North America. The Straightneck Group (T-SN) appears to be a much more recent development, judging from the low average GD value among straightneck cultivars (Table 2), consistent with its absence from the historical record prior to the late nineteenth century (Paris 2000a). Earlier results suggested that the Straightneck Group was derived from a cross between a cultivar of the Crookneck Group and a cultivar of the Acorn Group (Paris et al. 2003), but the present results (Table 2; Fig. 4) favor a direct derivation from the Crookneck Group.

The edible-fruited cultivar-groups of subsp. pepo

The five accessions of the Zucchini Group (ZU) are very closely related, having the lowest within-group GD value (Table 2). The zucchinis form a distinct sub-cluster (Fig. 2), as already observed using other markers (Katzir et al. 2000; Ferriol et al. 2003; Paris et al. 2003, 2004; Formisano et al. 2010). Another sub-cluster is formed by the three accessions representing a market type within the Pumpkin Group (PU), the oil-seed pumpkins, P-PU-GLE, P-PU-STY, and P-PU-WIE. Both, the zucchinis and the oil-seed pumpkins have a short history. The Zucchini Group apparently originated in the environs of Milan in the 
late nineteenth century (Paris 2000a). The oil-seed pumpkins derive from a recessive, hull-less mutation that occurred in Styria, Austria in the 1880s (Teppner 2000). The Pumpkin Group, the Vegetable Marrow Group (P-VM), and the Cocozelle Group (P-CO), which have considerably longer histories (Paris 2000a), have high within-group GD values (Table 2) and relative high heterozygosities (Online Resource 2). Their respective accessions, with the exception of a few pairings, are not clearly differentiated in the dendrogram (Fig. 2), the same as observed using other markers (Katzir et al. 2000; Paris et al. 2003; Ferriol et al. 2003).

\section{Evolutionary trends in subsp. pepo}

Principal coordinate analysis shows that subsp. pepo has a central core comprised mostly of Pumpkin Group (PU) accessions but also several each from the Vegetable Marrow Group (VM) and Cocozelle Group (CO), and one gourd (GP-OWA) (Fig. 5). The ancient Pumpkin Group (PU) has the majority of its cultivars within the core, the Vegetable Marrow (VM) cultivars are mostly positioned on the edge of the core, the Cocozelle (CO) cultivars are mostly more distant from the core, and the recent Zucchini Group (ZU) cultivars are all very distant from the core.

The strongly and interstitially ribbed pumpkins, PU-MOG and PU-750, are positioned in the center of the central core (Fig. 5). Teppner $(2000,2004)$ suggested that pumpkins of Guatemalan ancestry, which are distinguished from others by their strong and interstitial ribbing, constitute a separate subspecies from which evolved the other edible subsp. pepo. The exactly central positions of PU-MOG and PU-750 do not support the designation of a separate subspecies but are where the most primitive, ancestral pumpkins would be expected. As discussed by Teppner (2004), an ancient $C$. pepo fruit wall fragment from Oaxaca, southern Mexico (Smith 1997), shows the interstitial ribbing characteristic of these pumpkins.

Nearly all of the accessions of the Pumpkin Group (PU) in the central core (Fig. 5) are grown for the culinary use of their seeds, or are horticulturally unspecialized, as both the seeds and immature fruits or seeds and mature fruits are used for culinary purposes, ornament, or animal fodder. Their plants have vine growth habit (Table 1), are highly branched, strongly male, and late flowering and fruiting, in short, horticulturally primitive (Paris 2008). The few vegetable marrows (VM) and cocozelles (CO) in the core share most of these traits. In contrast, the majority of the accessions on the edge and outside of the core (Fig. 5) are horticulturally specialized. Most of them are grown exclusively for consumption of their young fruits, which must be harvested every few days, continually throughout the growing season. Their plants are less branched, not strongly male, have earlier flowering and fruiting, and bush growth habit (Table 1) which greatly facilitates crop management and harvest (Paris 2008). Three pumpkins having bush growth habit, PU-TON, PU-TOS, and PU-413, are positioned just outside the core. Most accessions of the Vegetable Marrow Group (VM) and Cocozelle Group (CO) are also found outlying to the core but they are bi-directionally distributed, to the top and to the left. The accessions most distant from the core are the most advanced horticulturally and include all accessions of the Zucchini Group (ZU); their plants are highly productive, nonbranching, bushy, and with an open growth habit facilitating even more the harvesting of immature fruits (Baggett 1972). Two twentieth-century developments, VM-CAS (Scarchuk 1954; All America Selections 2010) and PUGGL (Park Seed Catalog 1981), are positioned between the Cocozelle Group and the Zucchini Group and share most of their advanced traits. Outside the core but to the right are the hull-less-seed Pumpkin Group (PU) accessions specially developed for oil production and in yet another direction, to the bottom, are the small-fruited GP-LGM and GP-ROL, specially developed for eating the mature fruit flesh. Specialized accessions, those grown for exclusive use of the young fruits, mature fruits, or oil from their seeds, are the products of relatively recent, intensive breeding, and are positioned outside of the central core, and the different specializations radiate in different directions.

Fruit shape and evolution under domestication

Longfruitedness in cultivated cucurbit taxa is associated with the culinary use of their young fruits (Paris 1989). In Mediterranean countries and Europe, there is a long tradition, dating to antiquity, of use of young long, narrow melons, Cucumis melo, and bottle gourds, Lagenaria siceraria (Molina) Standley (Janick et al. 2007). Even the word cocozelle, a southern Italian dialect name, is a diminutive derivation from cocuzzi, bottle gourds, indicating the place of origin of the cultivar-group bearing this name (Paris 2000a). In Cucurbita pepo, selection for long fruits has reached its greatest extent in the Cocozelle Group, the fruits of which can attain a length-to-width ratio exceeding 5:1. Selection must have occurred twice, independently, in C. pepo subsp. pepo, as indicated by the differing positions of the four Balkan and Turkish cocozelles from the Italian and French cocozelles and zucchinis, toward the top and toward the left, respectively, in the principal coordinate analysis for subsp. pepo (Fig. 5).

A number of investigators have described and photographed fruits of various native Mexican and Guatemalan cultigens of Cucurbita pepo subsp. pepo (Zhiteneva 1930; Cutler and Whitaker 1967; Whitaker and Knight 1980; Merrick 1986; Lira 1995; Paris 2000a; Teppner, 2000). The 
fruits are ribbed and their shapes are much less diverse than in modern, commercially available cultivars, ranging from oblate, globose, and spherical (pumpkins), which constitute the vast majority, to oblong blocky (short vegetable marrows). The true-breeding, long-fruited cultigens of $C$. pepo subsp. pepo do not appear to be native to the Americas. Their abundance in Europe and Asia Minor (Zhiteneva 1930) indicates that their evolution was post-Columbian.

Even though domestication of subsp. pepo is thought to precede that of subsp. texana by approximately 5,000 years (Smith 2006), selection for deviation from fruit roundness occurred over 2,000 years earlier in subsp. texana, as indicated by rind fragments found in Kentucky (Watson and Yarnell 1966, 1969; Cowan 1997). Reflective of this earlier diversification into different fruit shapes are the higher GD values observed among the subsp. texana groupings (range of 0.33-0.41) than among the subsp. pepo groupings (range of $0.27-0.37$ ) (Table 2) as well as the clearer sub-clustering by cultivar-group within subsp. texana (Fig. 2). Selection toward deviation from roundness occurred twice within Cucurbita pepo subsp. texana, to flat scallop squash and to long crookneck squash.

Evolution under domestication for marked deviation from fruit roundness occurred four times in Cucurbita реро, twice (at least) in both domesticated subspecies. Repeated selection for this trait indicates that it was strongly desired. Deviation from the 1:1 length-to-width ratio of the fruit, by elongation or by flattening, results in a greater proportion of colored exocarp and firm mesocarp tissues, and less of the endocarp, to the total volume of the fruit (Sinnott and Durham 1929). The soft, seedy endocarp tissue is undesirable in young fruits that are consumed in their entirety. However, there is an inverse relationship between the length-to-width ratio of the fruit and seed size, seed length-to-width ratio (Paris and Nerson 2003), and seed yield (Nerson et al. 2000; Nerson 2005). Round fruits, that is, pumpkins, have larger, longer, and more seeds; long cylindrical fruits have smaller, shorter, and fewer seeds; fruit elongation exacts a cost on seed production. Traditionally, Guatemalan and Mexican pumpkins have been grown in a subsistence-type agriculture for consumption of their seeds or for dual usage of the seeds and fruits. In this type of economy, use of the seeds overrides the advantage bestowed by long fruits.

\section{Conclusions}

Before domestication, Cucurbita pepo evolved into three lineages, subsp. fraterna, which grows wild in northeastern Mexico, subsp. texana, which grows wild in the southeastern United States, and subsp. pepo, which has not been discovered in the wild but may have originated in southern
North America. Ornamental cultigens producing the smallest, round, striped fruits are located centrally between subsp. texana and subsp. pepo, suggesting that they are relicts of unknown wild progenitors. No cultigens closely related to subsp. fraterna have been identified. After domestication and long before the arrival of Europeans, subsp. texana evolved into several edible-fruited cultivargroups characterized by fruit shapes deviating from roundness. In subsp. pepo, the evolution of long-fruited cultivar-groups is more recent and occurred primarily in Europe. Although there is no obvious genetic barrier to crossing among the subspecies, none of the cultivar-groups and none of the accessions examined appears to derive from such crossing.

Acknowledgments For providing seed samples gratis, we thank K. Reitsma of the North Central Plant Introduction Station, Ames, Iowa; M. Manoah, A.R.O. Volcani Center, Bet Dagan, Israel; G. Santini, S.A.I.S., Cesena, Italy; G.P. Silvestri, C.C.S.A., Fidenza, Italy; Y. Asherov, Institute of Vegetable Seed Quality, Samarqand, Uzbekistan; H.D. Wilson, Texas A\&M University, College Station; T.C. Andres, The Cucurbit Network, Bronx, New York; and P.S. Lichtenecker, Vienna, Austria. This research was financially supported by the Austrian Science Fund (FWF project No. P19662-B16) and the by the State of Lower Austria.

Open Access This article is distributed under the terms of the Creative Commons Attribution Noncommercial License which permits any noncommercial use, distribution, and reproduction in any medium, provided the original author(s) and source are credited.

\section{References}

All America Selections (2010) AAS winners 1933 to present. http:// www.all-americaselections.org/AAS_Winners.asp?sort1=Year_ Won\&Sort2=ASC\&Submit=Submit. Accessed 29 Dec 2010

Andres TC (1987) Cucurbita fraterna, the closest wild relative and progenitor of C. pepo. Cucurbit Genet Coop Rep 10:69-71

Baggett JR (1972) Open growth habit in summer squash. HortScience $7: 288$

Bailey LH (1943) Species of Cucurbita. Gent Herb 6:265-322

Blanca J, Cañizares J, Roig C, Ziarsolo P, Nuez F, Picó B (2011) Transcriptome characterization and high throughput SSRs and SNPs discovery in Cucurbita pepo (Cucurbitaceae). BMC Genomics 12:104. doi:10.1186/1471-2164-12-104

Carter GF (1945) Plant geography and culture history in the American southwest. Viking Fund Publications in Anthropology No. 5, New York

Cowan CW (1997) Evolutionary changes associated with the domestication of Cucurbita pepo, evidence from eastern Kentucky. In: Gremillion KJ (ed) People, places, and landscapes: studies in paleoethnobotany. University of Alabama Press, Tuscaloosa, pp 63-85

Cutler HC, Whitaker TW (1967) Cucurbits from the Tehuacan caves. In: Byers DS (ed) The prehistory of the Tehuacan Valley, vol 1. Univeresity of Texas, Austin, pp 212-219

Decker DS (1985) Numerical analysis of allozyme variation in Cucurbita pepo. Econ Bot 39:300-309 
Decker DS (1988) Origin(s), evolution, and systematics of Cucurbita pepo (Cucurbitaceae). Econ Bot 42:4-15

Decker DS, Wilson HD (1987) Allozyme variation in the Cucurbita pepo complex: C. pepo var. ovifera vs. C. texana. Syst Bot $12: 263-273$

Decker-Walters DS (1990) Evidence for multiple domestications of Cucurbita pepo. In: Bates DM, Robinson RW, Jeffrey C (eds) Biology and utilization of the Cucurbitaceae. Cornell University Press, Ithaca NY, pp 96-101

Decker-Walters DS, Staub JE, Chung SM, Nakata E, Quemada HD (2002) Diversity in free-living populations of Cucurbita pepo (Cucurbitaceae) as assessed by random amplified polymorphic DNA. Syst Bot 27:19-28

Duchesne AN (1786) Essai sur l'histoire naturelle des courges. Panckoucke, Paris

Edelstein M, Paris HS, Nerson H (1989) Dominance of the bush growth habit in spaghetti squash. Euphytica 43:253-257

Emerson RA (1910) The inheritance of sizes and shapes in plants. Am Nat 44:739-746

Ferriol M, Pico B, Nuez F (2003) Genetic diversity of a germplasm collection of Cucurbita pepo using SRAP and AFLP markers. Theor Appl Genet 107:271-282

Formisano G, Paris HS, Frusciante L, Ercolano MR (2010) Commercial Cucurbita pepo squash hybrids carrying disease resistance introgressed from Cucurbita moschata have high genetic similarity. Plant Genet Resour 8:198-203

Gong L, Stift G, Kofler R, Pachner M, Lelley T (2008) Microsatellites for the genus Cucurbita and an SSR-based genetic linkage map of Cucurbita pepo L. Theor Appl Genet 117:37-48

Hampl V, Pavlícek A, Flegr J (2001) Construction and bootstrap analysis of DNA fingerprinting-based phylogenetic trees with a freeware program FreeTree: application to trichomonad parasites. Intl J Syst Evol Microbiol 51:731-735

Ignart F, Weeden NF (1984) Allozyme variation in cultivars of Cucurbita pepo L. Euphytica 33:779-785

Janick J, Paris HS, Parrish MC (2007) The cucurbits of Mediterranean antiquity: identification of taxa from ancient images and descriptions. Ann Bot 100:1441-1457

Kashi Y, King DG (2006) Simple sequence repeats as advantageous mutators in evolution. Trends Genet 22:253-259

Kashi Y, King DG, Soller M (1997) Simple sequence repeats as a source of quantitative genetic variation. Trends Genet 13:74-78

Katzir N, Danin-Poleg Y, Tzuri G, Karchi Z, Lavi U, Cregan PB (1996) Length polymorphism and homologies of microsatellites in several Cucurbitaceae species. Theor Appl Genet 93:12821290

Katzir N, Tadmor Y, Tzuri G, Leshzeshen E, Mozes-Daube N, DaninPoleg Y, Paris HS (2000) Further ISSR and preliminary SSR analysis of relationships among accessions of Cucurbita pepo. In: Katzir N, Paris HS (eds) Proceedings of Cucurbitaceae 2000. Acta Hort, vol 510, pp 433-439

King DG, Trifonov EN, Kashi Y (2006) Tuning knobs in the genome: evolution of simple sequence repeats by indirect selection. In: Caporale LH (ed) The implicit genome. Oxford University Press, New York, pp 77-90

Lebeda A, Widrlechner MP, Staub J, Ezura H, Zalapa J, Kristkova E (2007) Cucurbits (Cucurbitaceae; Cucumis spp., Cucurbita spp., Citrullus spp.). In: Singh RJ (ed) Genetic resources, chromosome engineering, and crop improvement, vol 3. CRC Press, Boca Raton, pp 271-376

Li Y, Korol A, Fahima T, Bailes A, Nevo E (2002) Microsatellites: genomic distribution, putative functions and mutational mechanisms: a review. Mol Ecol 11:2453-2465

Lira R (1995) Estudios taxonomico y ecogeograficos de las Cucurbitaceae Latinoamericanas de importancia economica. IPGRI, Rome, p 244
Lira R, Montes S (1994) Cucurbits (Cucurbita spp.). In: Hernandez JE, Leon J (eds) Neglected crops, 1492 from a different perspective. F.A.O, Rome, pp 63-77

Merrick LC (1986) Wild and cultivated cucurbits from the Sierra Madre Occidental of northwest Mexico and the Rio Balsas Valley of southeast Mexico. Final Report, IBPGR Project \#85-79

Naudin C (1859) Nouvelles recherches sur les caractères spécifiques et les variétés des plantes du genre Cucurbita. Ann Sci Nat Bot Ser 4(6):5-73

Nee M (1990) The domestication of Cucurbita (Cucurbitaceae). Econ Bot 44(Suppl 3):56-68

Nei M, Li WH (1979) Mathematical model for studying genetic variation in terms of restriction endonucleases. Proc Natl Acad Sci USA 76:5269-5273

Nerson H (2005) Effects of fruit shape and plant density on seed yield and quality of squash. Sci Hort 105:293-304

Nerson H, Paris HS, Paris EP (2000) Fruit shape, size and seed yield in Cucurbita pepo. In: Katzir N, Paris HS (eds) Proceedings of Cucurbitaceae 2000. Acta Hort, vol 510, pp 227-230

Paris HS (1986) A proposed subspecific classification for Cucurbita pepo. Phytologia 61:133-138

Paris HS (1989) Historical records, origins, and development of the edible cultivar groups of Cucurbita pepo (Cucurbitaceae). Econ Bot 43:423-443

Paris HS (2000a) History of the cultivar-groups of Cucurbita pepo. Hort Revs 25(2001):71-170 4 pl

Paris HS (2000b) Paintings by A.N. Duchesne and the history of Cucurbita pepo. Ann Bot 85:815-830

Paris HS (2001) Characterization of the Cucurbita pepo collection at the Newe Ya'ar Research Center, Israel. Plant Genet Resourc Newslett 126:41-45

Paris HS (2007) The drawings of Antoine Nicolas Duchesne for his natural history of the gourds. In: Érard C (ed). Muséum National d'Histoire Naturelle, Paris

Paris HS (2008) Summer squash. In: Prohens J, Nuez F (eds) Handbook of plant breeding, Vegetables I. Springer, New York, pp 351-379

Paris HS, Brown RN (2005) The genes of pumpkin and squash. HortScience 40:1620-1630

Paris HS, Nerson H (2003) Seed dimensions in the subspecies and cultivar-groups of Cucurbita pepo. Genet Resourc Crop Evol 50:615-625

Paris HS, Yonash N, Portnoy V, Mozes-Daube N, Tzuri G, Katzir N (2003) Assessment of genetic relationships in Cucurbita pepo (Cucurbitaceae) using DNA markers. Theor Appl Genet 106:971-978

Paris HS, Portnoy V, Mozes-Daube N, Tzuri G, Katzir N, Yonash N (2004) AFLP, ISSR, and SSR polymorphisms are in accordance with botanical and cultivated plant taxonomies of the highly polymorphic Cucurbita pepo. In: Davidson CG, Trehane P (eds) Proc 26th International Horticultural Congress. Acta Horticulturae, vol 634, pp 167-173

Paris HS, Daunay M-C, Pitrat M, Janick J (2006) First known image of Cucurbita in Europe, 1503-1508. Ann Bot 98:41-47

Park Seed Catalog (1981) Flowers and vegetables. Geo W Park Seed Co, Greenwood, p 7

Queller DC, Strassmann JE, Hughes CR (1993) Microsatellites and kinship. Trends Ecol Evol 8:285-288

Sanjur OI, Piperno DR, Andres TC, Wessel-Beaver L (2002) Phylogenetic relationships among domesticated and wild species of Cucurbita (Cucurbitaceae) inferred from a mitochondrial gene: implications for crop plant evolution and areas of origin. Proc Natl Acad Sci USA 99:535-540

Scarchuk J (1954) Fruit and leaf characters in summer squash. J Hered 45:295-297 
Schaffer AA, Boyer CD, Paris HS (1986) Inheritance of rind lignification and warts in Cucurbita pepo L. and a role for phenylalanine ammonia lyase in their control. Z Pflanzenzücht 96:147-153

Shifriss O (1965) The unpredictable gourds. Am Hort Mag 44:184-201

Sinnott EW (1927) A factorial analysis of certain shape characters in squash fruits. Am Nat 61:333-334

Sinnott EW, Durham GB (1929) Developmental history of the fruit in lines of Cucurbita pepo differing in fruit shape. Bot Gaz $87: 411-421$

Smith BD (1997) The initial domestication of Cucurbita pepo in the Americas 10,000 years ago. Science 276:932-934

Smith BD (2006) Eastern North America as an independent center of plant domestication. Proc Natl Acad Sci USA 103:12223-12228

Stift G, Zraidi A, Lelley T (2004) Development and characterization of microsatellite markers (SSR) in Cucurbita species. Cucurbit Genet Coop Rep 27:61-65

Teppner H (2000) Cucurbita pepo (Cucurbitaceae)—history, seed coat types, thin coated seeds and their genetics. Phyton (Horn) 40:1-42

Teppner H (2004) Notes on Lagenaria and Cucurbita (Cucurbitaceae)-review and new contributions. Phyton (Horn) 44:245308
Watson PJ, Yarnell RA (1966) Archaeological and paleoethnobotanical investigations in Salts Cave, Mammoth Cave National Park, Kentucky. Am Antiq 31:842-849

Watson PJ, Yarnell RA (1969) The prehistory of Salts Cave, Kentucky. Reports of investigations 16, Springfield

Whitaker TW (1947) American origin of the cultivated cucurbits. Ann Missouri Bot Gard 34:101-111

Whitaker TW, Carter GF (1946) Critical notes on the origin and domestication of the cultivated species of Cucurbita. Am J Bot 33:10-15

Whitaker TW, Cutler HC (1971) Pre-historic cucurbits from the valley of Oaxaca. Econ Bot 25:123-127

Whitaker TW, Cutler HC (1986) Cucurbits from preceramic levels at Guila Naquitz. In: Flannery KV (ed) Guila Naquitz: archaic foraging and early agriculture in Oaxaca, Mexico. Academic Press, Orlando, pp 275-279

Whitaker TW, Davis GN (1962) Cucurbits. Interscience, New York

Whitaker TW, Knight RJ (1980) Collecting cultivated and wild cucurbits in Mexico. Econ Bot 34:312-319

Wilson HD, Doebley J, Duvall M (1992) Chloroplast DNA diversity among wild and cultivated members of Cucurbita. Theor Appl Genet 84:859-865

Zhiteneva NE (1930) The world's assortment of pumpkins. Trudy Prikl Bot Genet Selek 23:157-207 